\title{
ASSIMETRIA NA COMUNICAÇÃO UBÍQUA: A ENCENAÇÃO DE UM ATO DE LINGUAGEM NO TWITTER
}

\section{ASYMMETRY IN UBIQUITOUS COMMUNICATION: THE STAGING OF A SPEECH ACT ON TWITTER}

\author{
Luis Henrique Boaventura(UPF) ${ }^{54}$ \\ Ernani Cesar de Freitas (UPF)
}

\begin{abstract}
RESUMO:Este artigo investiga a assimetria entre a produção e a interpretação do ato de linguagem em uma comunicação ubíqua, especificamente em um só post de uma só plataforma de rede social, o Twitter.O objetivo é analisar fenômenos linguageiros que resultam nessa assimetria. Os marcos teóricos se situam na semiolinguística de Charaudeau (2001, 2010a, 2010b), na comunicação ubíqua de Santaella (2010, 2013a, 2014) e na filosofia do ato responsável (ato ético), de Bakhtin (1997, 2012). O corpus do artigo é uma mensagem postada no Twitter pela jornalista libanesa OctaviaNasr, da CNN, que acabou desencadeando sua demissão.A pesquisa é descritiva, bibliográfica com abordagem qualitativa. Como resultado, foi apurado que as estratégias discursivas da locutora não atingiram sua finalidade em função da projeção involuntária de um segundo EUe (profissional), percebido por TUi à revelia do EUe (pessoal) projetado de acordo com suas estratégias. Isto levou à assimetria do ato de linguagem, porque EUe (mesmo que múltiplo,habitando diversos lugares no espaço virtual-discursivo) está ligado a EUc, e porque este, ser social, ocupaum espaço singular no mundo, existindo consequências a serem enfrentadas no mundo real, neste caso a demissão da jornalista de sua posição na CNN.
\end{abstract}

PALAVRAS-CHAVE: Assimetria comunicativa. Ato ético.Hipermobilidade. Comunicação ubíqua. Twitter.

ABSTRACT: This article investigates the asymmetry between the production and the interpretation of the speech act in a ubiquitous communication, specifically in one post of one platform of social network, the Twitter. The goal is to analyze linguistic phenomenons that result in this asymmetry. The theoretical frameworks are ser in Charaudeau's semiolinguistics (2001, 2010a, 2010b), Santaella's ubiquitous communication (2010, 2013a, 2014) and Bakhtin's philosophy of the responsible act (ethical act) $(1997,2012)$. The article corpus is a message posted on Twitter by Lebanese CNN journalist Octavia Nasr that ended up triggering her resignation. The research is descriptive, bibliographic with a qualitative approach. As a result, it was found that the speaker's discursive strategies did not achieve its purpose due to the involuntary projection of a second EUe (professional), perceived by TUi despite EUe (personal) designed according to her strategies. This led to the asymmetry of the speech act because EUe (even multiple, inhabiting various places in the virtual-discursive space) is connected to EUc, and because this, being social, occupies a unique place in the world, and there are consequences to be faced in this real world, in this case the resignation of the journalist from her position at CNN.

KEYWORDS: Communicative asymmetry. Ethical act.Hypermobility. Ubiquitous communication. Twitter.

\section{Introdução}

Em julho de 2010, a veterana editora da CNN para assuntos do Oriente Médio, OctaviaNasr, postou em sua conta no Twittera seguinte mensagem: "Triste ao saber da morte de Sayyed Mohammad Hussein Fadlallah. Um dos gigantes do Hezbollah a quem respeito muito... \#Líbano" (NASR, 2012, tradução nossa) ${ }^{56}$. O tweet se difundiu rapidamente e gerou reações por toda a web. Logo já não importava quem era OctaviaNasr, jornalista libanesa

\footnotetext{
${ }^{54}$ Doutor em Letras (UPF); professor na Faculdade de Educação Superior de Chapecó - FACESC. Email: luishboaventura@hotmail.com.

55 Doutor em Letras (PUCRS); pós-doutorado em Linguística Aplicada e Estudos da Linguagem (PUCSP/LAEL); professor permanente do Programa de Pós-graduação em Letras da Universidade de Passo Fundo (UPF); e-mail: nanicesar@terra.com.br.

${ }^{56}$ Sad to hear of the passing of Sayyed Mohammad Hussein Fadlallah. One of Hezbollah's giants I respect a lot... \#Líbano.
} 
radicada em Nova York, dona de uma carreira brilhante de mais de duas décadas na maior cadeia de notícias do mundo; importava sim o fato de que uma importante figura da americana CNN lamentara a morte de um homem considerado pelos EUA um líder terrorista. A demissão de Nasr foi comunicada dois dias depois.É possível que antes do advento das redes sociais e das recentes revoluções na comunicação, seria preciso mais do que cento e quarenta caracteres para pôr fim a uma carreira de vinte anos, mas aparentemente, no Twitter, bastam duas palavras: "triste" e "respeito". Tivesse Nasr postado "soube da morte de Sayyed Mohammad Hussein Fadlallah, um dos gigantes do Hezbollah. \#Líbano", segundo ela própria $^{57}$, é bem provável quenada tivesse ocorrido (embora algo ainda possa ser inferido da palavra "gigante"). Seria simplesmente notícia, com escrutínio fechado para convicções pessoais. O sentimento carregado na palavra "triste" e aopinião expressa na palavra "respeito" tornaram sua posição na $\mathrm{CNN}$ insustentável. Atualmente Nasré anfitriã do programa KalamNawaem, da MBC, na Arábia Saudita - a pouco mais de 10 mil quilômetros de Nova York.

O caso de Nasr, corpus de nosso artigo, é apenas um dos muitos em que profissionais da comunicação não conseguemprecisamente comunicar e terminam advertidos, afastados ou, não raro, demitidos - com carreira e credibilidade severamente abaladas. Declarações como a de OctaviaNasr no Twitter, Facebook, Instagrametc. partilham entre si o mesmo rol de justificativas: falta de intimidade com redes sociais, erro de cálculo quanto à dimensão de algo dito na rede, lapso de consciência, vitória de um impulso. "O que aconteceu comigo pode acontecer com qualquer um a qualquer momento", disse Nasr (2012, tradução nossa) ${ }^{58}$ em entrevista ao IJNet.Mais do que acontecer com qualquer um, entretanto, acontece especificamente com jornalistas, em quantidade e frequência cada vez maiores. O porquê de profissionais da comunicação sofrerem revesesao operar uma ferramenta básica (e essencial ao seu trabalho) como o Twitter e outras redes sociais é uma constante que demanda diagnóstico.

Esclarecer esse tema envolverá compreender o discurso projetado na hipermídia de acordo com Lucia Santaella(2010, 2013a, 2014)sob noções que vão da filosofia do ato responsável, de Bakhtin(1997, 2012), à análise semiolinguística do discurso, de Charaudeau(2001, 2010a, 2010b). A pesquisa caracteriza-se comodescritiva, bibliográfica e se desenvolve mediante abordagem qualitativa utilizando a análise do discurso. O caso será analisado segundo a semiolinguística e a filosofia do ato responsável interpelados pelo estudo da comunicação ubíqua; serão verificados os elementos e a conjectura das mensagens que compõem o ato de linguagem, assim como os sujeitos, os modos de organização do discurso, as estratégias discursivas, a assimetria do ato e o intercâmbio de efeitos entre os circuitos interno e externo deste ato.

$\mathrm{O}$ artigo é composto por "2O ato ético e a assimetria na comunicação ubíqua", que se subdivide em "2.1 O ato ético na comunicação ubíqua", 2.2 "Encenação e assimetria no ato de linguagem" e 2.3 "Assimetria do ato de linguagem na comunicação ubíqua". Na sequência, tratamos de "3 Procedimentos metodológicos" e "4 assimetria, ato ético e ubiquidade: um tweet sob análise", encerrando com as considerações finais.

\section{$2 \mathrm{O}$ ato ético e a assimetria na comunicação ubíqua}

\section{$2.1 \mathrm{O}$ ato ético na comunicação ubíqua}

É notável o desafio de conceber a filosofia do ato responsável de Bakhtin (2012), fundada principalmente sobre uma noção de identidade e individualidade (ocupar um lugar

\footnotetext{
${ }^{57}$ If I must tweet, I would've tweeted that he passed away without any extra information. (NASR, 2012)

${ }^{58}$ What happened with me can happen with anyone at any time.
} 
singular no mundo), dentro de uma conjectura como a atual, em que o indivíduo parece se desmaterializar e rarefazer sob a compressão do não-território, do não-espaço, "local" onde real e virtual se amalgamam e onde pontos de referência se tornam confusos ou mesmo irrastreáveis, a comunicação torna-se ubíqua e o sujeito vive em hipermobilidade. Santaella e Lemos (2010) chamaram a este contexto "era dos fluxos" (em oposição a "era da navegação").

\begin{abstract}
A mudança de paradigma entre a era da navegação e a dos fluxos é brutal. Ela significa a transição entre um mundo onde a informação pertencia a uma esfera separada do nosso cotidiano, a era onde falávamos em "virtual" como uma dimensão à parte da vida humana, bem no espírito dos anos 1990: "virtual" era tomado como paralelo e distinto de "real". Na era dos fluxos, virtual e real são sentidos como se fossem uma só e mesma coisa - uma mesma rede integrada através de dispositivos híbridos (SANTAELLA; LEMOS, 2010, p. 94).
\end{abstract}

Se real e virtual se confundem, os pontos de referência passam de estáveis a voláteis e a constituição de identidades bem delimitadas fica comprometida, obscurecendo o quadro de encenação de um ato de linguagem praticado (de forma integral ou em parte) na rede. De acordo com Charaudeau (2010b, p. 68), "a identidade dos parceiros engajados na troca é a condição que requer que todo ato de linguagem dependa dos sujeitos que aí se acham inscritos"; apesar de elípticos, os sujeitos estão presentes e as palavras de Charaudeau são válidas para qualquer plataforma, ainda que fluida e movediça, onde um ato de linguagem é suportado: há sujeitos reais, determinados socialmente, por detrás deste palco onde os atores do discurso representam seu jogo de cena, e a responsabilidade pelo que diz o ser projetado (EUe) recai irremediavelmente sobre o ser real (EUc) em razão da fragilidade dos limites que separam o espaço interno (virtual) do espaço externo (real). Esta necessidade de resposta e impossibilidade de fuga à responsabilidade por sua enunciação implica a concepção bakhtiniana de ato ético e, consequentemente, o tom ea valoração estética do discurso.

Bakhtin $(1997,2012)$ entende o ato ético como a ocupação de um lugar ímpar no mundo, a partir do qual ele contrai a responsabilidade de responder por seus atos (ato responsivel). De acordo com Bakhtin (2012, p. 96, grifo do autor), não existe álibi na vida.

[...] eu também sou participante no existir de modo singular e irrepetível, e eu ocupo no existir singular um lugar único, irrepetível, insubstituível e impenetrável da parte de um outro. [...] A singularidade do existir é irrevogavelmente obrigatória. Este fato do meu não-álibi no existir, que está na base do dever concreto e singular do ato, não é algo que eu aprendo e do qual tenho conhecimento, mas algo que eu reconheço e afirmo de um modo singular e único [...], cada existir é único.

O sujeito, imbuído de sua individualidade e ocupante de um lugar único no mundo, possui a responsabilidade pelo que enuncia a partir deste lugar. Enquanto ser singular, não há fuga possível às consequências do seu ato, como esperam muitos dos envolvidos em casos como o selecionado aqui para análise: proliferam-se declarações como "era apenas uma brincadeira", "fui mal interpretado", "fui hackeado", "foi meu sobrinho de sete anos". Este inescapável preceito bakhtiniano aponta para a constituição da própria identidade do sujeito, do seu posicionamento enquanto indivíduo; um posicionamento cada vez mais difícil de apontar na era dos fluxos.

A identidade conferida pela posição exata no mundo é fundamental, pois transfere ao sujeito o ônus da responsabilidade. Sobral (2008, p. 233) lembra que "para a concepção do ato ético de Bakhtin, agir é sempre comprometer-se, agir é sempre ser interpelado pelo outro do ponto de vista ético, agir é sempre ser chamado à responsabilidade e à responsividade". Neste panorama, o estilo ou "tom" é o ponto de convergência para o ato ético. Sobral (2008, p. 232) ainda destaca que 
a valoração/avaliação ética que o agente tem de fazer de seus próprios atos é o elemento unificador de todos os atos de sua atividade. Trata-se de um ato de avaliação "responsível" em que se fazem presentes o processo do ato, ou sua singularidade, o conteúdo do ato, ou sua generalidade, e o agente como sujeito que avalia seus atos/feitos singulares no âmbito da generalidade dos atos/atividades. O sujeito não está sozinho: o valor de seus atos, a avaliação/valoração que o sujeito faz deles é o valor que eles têm para o agente, em vez de um valor absoluto que se impusesse a ele, mas cabe insistir que essa valoração/avaliação ocorre numa situação de interação com outros sujeitos.

A partir deste espaço singular o sujeito poderá interagir com outros, de acordo com a conhecida perspectiva dialógica para a qual frequentemente convergem os textos bakhtinianos. O estilo, que pode diferenciar, por exemplo, um tweet franco de outro irônico, é concebido em função do destinatário, base sobre a qual Charaudeau (2001, 2010a, 2010b) viria a fundar a semiolinguística. A esse respeito, Bakhtin (1997, p. 320) pergunta: "a quem se dirige o enunciado? Como o locutor (ou o escritor) percebe e imagina seu destinatário? É disso que depende a composição, e sobretudo o estilo, do enunciado". É sobre este "imaginar", esta projeção, que o locutor constrói/encena seu discurso e concebe este ato ético, conforme Bakhtin (2012), como um ato de linguagem, conforme Charaudeau (2010a), ou seja, a possibilidade de agir através da linguagem.

\subsection{Encenação e assimetria do ato de linguagem}

A noção de ato de linguagem para Charaudeau descende de uma abordagem interacionista (CHARAUDEAU; MAINGUENEAU, 2008). Como explica o linguista (2001, p. 28), "esse termo não é, aqui, tomado no sentido que lhe dá a Pragmática, mas sim em um sentido mais extenso, uma vez que ele designa o conjunto da realidade linguageira". Conserva-se, entretanto, a ideia de "agir por meio da linguagem" (CHARAUDEAU; MAINGUENEAU, 2008, p. 72), "edificada" pela teoria dos speechacts. Charaudeau (2001) entende "ato de linguagem" como o combinado entre circuitos interno e externo do ato onde se estabelece o contrato de comunicaçã $o^{59}$ sob o qual o sujeito desenvolve estratégias discursivas para seduzir ou persuadir seu destinatário. "Considerar os enunciados como atos é, então, admitir que eles são realizados para agir sobre os outros, mas também levá-los a reagir: o dizer não é somente fazer, mas também fazer fazer" (CHARAUDEAU; MAINGUENEAU, 2008, p. 73, grifo dos autores).

Nos jogos discursivos do ato de linguagem, Charaudeau e Maingueneau (2008) resgatam em Benveniste (1988) a relação interdependente entre um EU e um TU como atores do discurso. Contudo, esse ato de linguagem institui o jogo não entre dois sujeitos comunicacionais apenas, mas quatro. Trata-se de "um fenômeno que combina o dizer e o fazer" (CHARAUDEAU, 2001, p. 28, grifo do autor), entendendo-se "fazer" por instância situacional, espaço das restrições, e "dizer" por instância discursiva, espaço das estratégias. Este modelo duplica a interação EU-TU da enunciação ao concebê-la nestes dois campos de ação: um circuito externo (instância situacional) e um circuito interno (instância discursiva), ligados entre si por um contrato de comunicação, compondo assim o ato de linguagem.

Os sujeitos, portanto, são quatro: EUc, EUe; TUi, TUd. EUc (sujeito comunicante) e TUi (sujeito interpretante) são seres reais, determinados socialmente. EUe (sujeito enunciador) e TUd (sujeito destinatário) são seres da fala. EUc, sujeito com identidade psicossocial, projeta em seu ato de linguagem uma certa imagem de si mesmo, um sujeito que só existe nos limites daquele ato: o EUe. Este sujeito é uma encenação de EUc com a

\footnotetext{
${ }^{59} \mathrm{O}$ contrato de comunicação é o "conjunto das condições nas quais se realiza qualquer ato de comunicação [...]” (CHARAUDEAU; MAINGUENEAU, 2008b, p. 132).
} 
pretensão de alcançar sua finalidade comunicacional, de surtir seus efeitos de sentido. Consequentemente, ele "é sempre uma imagem de fala que oculta em maior ou menor grau o EUc" do ponto de vista do sujeito interpretante (TUi) (CHARAUDEAU, 2010a, p. 51). A figura "O ato de linguagem e seus sujeitos" (Figura 1, a seguir) concebida por Charaudeau representa hoje, com ênfase, a esquize de sujeitos replicantes que se partem e se multiplicam na plataforma reticular da web, conforme define Santaella (2003, p. 126).

\begin{abstract}
Esse sujeito se transforma na era digital em um sujeito multiplicado, disseminado e descentrado, continuamente interpelado como uma identidade instável [...], como um processo contínuo de formação de múltiplas identidades, instaurando formações sociais que não podem mais ser chamadas de modernas, mas pós-modernas.
\end{abstract}

O espaço de ação onde é desempenhado o ato de linguagem é reproduzido por Charaudeau (2010a) em um esquema binário, composto pelo circuito interno e pelo circuito interno do dispositivo deste ato. O circuito externo é a arena dos interlocutores, que Charaudeau (2010a) chama de parceiros. Eles são seres sociais, reais, historicamente determinados e donos de intenções. São os seres do "fazer", logo: o sujeito comunicante (EUc) e o sujeito interpretante (TUi). Já o circuito interno é o espaço discursivo, dos seres defala (que Charaudeau também chama de "protagonistas da enunciação", de "estatuto exclusivamente linguageiro"), onde é operada a encenação do ato de linguagem para o sujeito interpretante (um ser social), do outro lado da arena, no espaço situacional junto ao sujeito comunicante. Essa situação de comunicação pode ser ilustrada pelo esquema apresentado na Figura 1:

\title{
Figura 1 - $O$ ato de linguagem e seus sujeitos
}

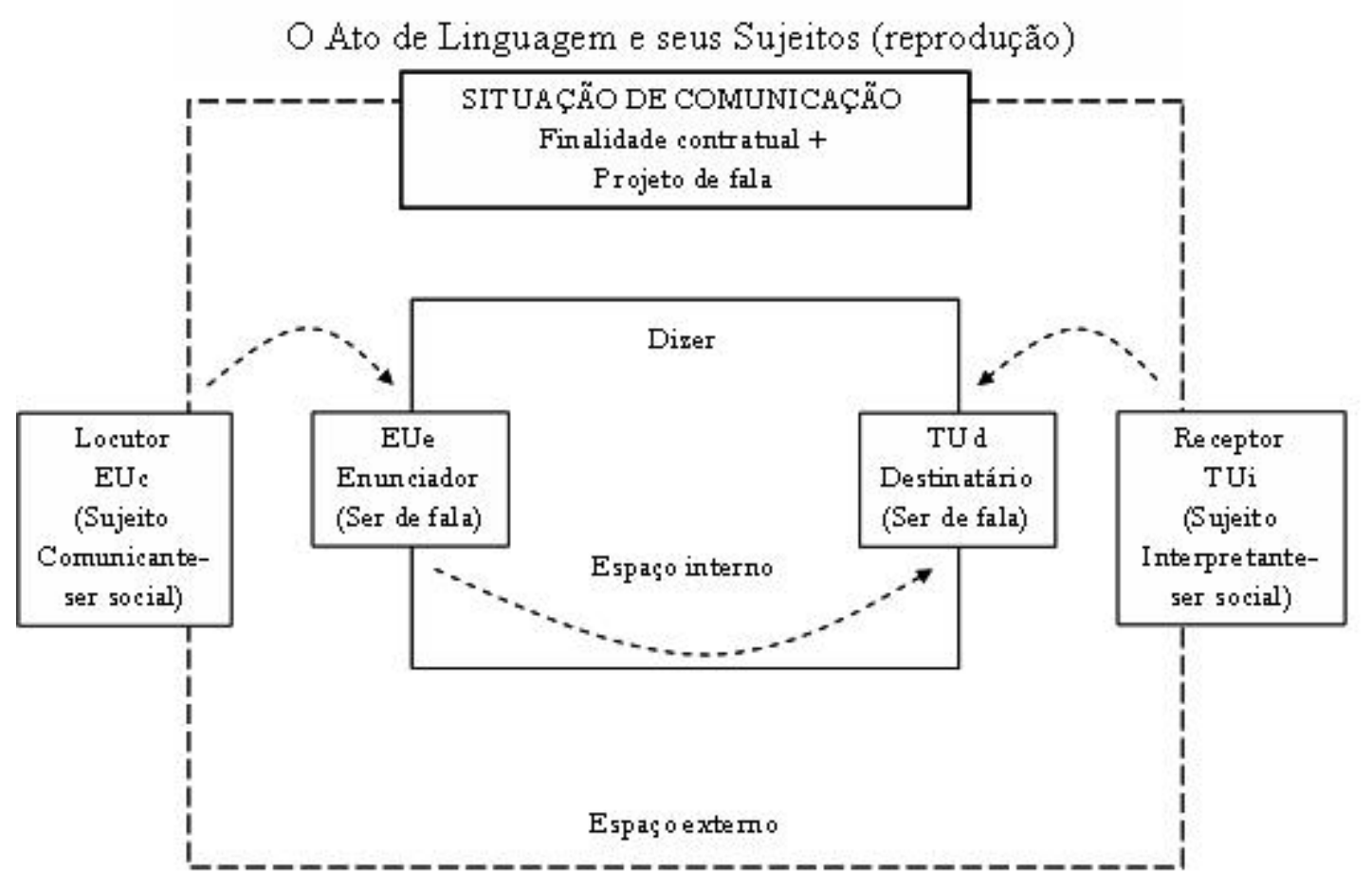

Fonte: Charaudeau (2010a, p. 77)

A concepção de Charaudeau (2010a) para o sujeito, desse modo, amplifica a oposição benvenisteana simples EU/TU para um duplo paralelo:EUc, EUe; TUi, TUd. Esta perspectiva enquadra-se em um dispositivo de situação de comunicação, regido por sua vez por um 
contrato de comunicação que, embora imponha coerções, também abre espaços de manobra para os sujeitos testarem estratégias de discurso.

O espaço de estratégias está diretamente relacionado ao nível discursivo da linguagem; é o espaço onde o sujeito possui certa liberdade (certa "margem de manobra") para operar a mise-en-scène (encenação). De acordo comCharaudeau (2010a, p. 76, grifo do autor), "fala-se (ou escreve-se) organizando o discurso em função de sua própria identidade, da imagem que se tem de seu interlocutor e do que já foi dito". O sujeito irá pôr seu discurso em cena (e pôrse, por conseguinte) visando a determinado objetivo, que, para ser correspondido, demanda a elaboração de uma estratégia de discurso.

Charaudeau (2010a) propõe três estratégias discursivas: a estratégia de legitimação, que outorga ao sujeito enunciador o direito à palavra e a possibilidade de ser ouvido; a estratégia de credibilidade, por meio da qual o sujeito visa a alcançar uma posição de confiabilidade junto a seu interlocutor; e a estratégia de captação, responsável por seduzir ou persuadir o sujeito destinatário, levando-o a "entrar no universo do pensamento que é o ato de comunicação" para que assim "partilhe a intencionalidade, os valores e as emoções dos quais esse ato é portador" (CHARAUDEAU; MAINGUENEAU, 2008b, p. 93). As duas primeiras estratégias fazem parte de um conjunto que licencia o locutor a falar e ser ouvido, já a terceira tem a prerrogativa de persuadir o interlocutor ou mesmo de convencê-lo. As estratégias discursivas não se excluem e com frequência operam simultaneamente.

Ocorre assimetria no ato de linguagem quando há desencontro entre os processos de produção e de interpretação do ato de linguagem (CHARAUDEAU, 2010a). A estratégia discursiva de captação é elemento chave em casos de assimetria do ato de linguagem; quando ela não atinge seu objetivo, significa que a interpretação do TU não correspondeu à intencionalidade do EU quando este enunciou seu ato de linguagem. Em um contexto de comunicação ubíqua, traçar uma estratégia de captação que envolva uma projeção de TUd (sujeito de discurso) compatível com TUi (sujeito real) é problemático por uma série de razões que investigaremos na sequência - isolar a posição física e social dos sujeitos, sua bagagem cultural e de valores pré-discursivos, prever as condições de uma plataforma de discurso suspensa no virtual.

\subsection{Assimetria do ato de linguagem na comunicação ubíqua}

O quadro comunicacional de Charaudeau (2010a), embora esteja fixado em uma plataforma suficientemente maleável de acordo com a situação de comunicação compreendida por ele, ainda prevê parâmetros concretos, uma situação de comunicação conhecida, um contrato inteligível, um EUc que projeta seres de fala (EUe e TUd) de acordo com um TUisemiencoberto. Mas quando se considera uma plataforma líquida e instável (SANTAELLA; LEMOS, 2010) como a rede social, sobretudo uma rede de sentenças curtas e poucos recursos para mise-en-scène como o Twitter, convém aceitar que o EUc nem sempre sabe ao certo sobre que palco está projetando seus seres de fala, nem se a situação de comunicação, situada no interregno misto do real e do virtual, embaralhados nos múltiplos espaços da ubiquidade (SANTAELLA, 2013a), corresponde à realidade, o que pode inviabilizar todas as estratégias discursivas que se imaginou empreender por ser este um contrato de termos escusos, firmado com um TUi sem rosto e estilhaçado em milhões de personalidades distintas que formam uma instituição destinatária caótica e imprevisível. $\mathrm{O}$ locutor das redes sociais não projeta seres bem determinados em uma arena sólida, projeta nefelibatas sobre uma nuvem: o sujeito ubíquo.

O sujeito ubíquo vem complementar os três tipos de sujeito que teoriza Santaella (2004): o contemplativo, o movente e o imersivo. 


\begin{abstract}
O leitor contemplativo é o leitor meditativo da idade pré-industrial, da era do livro impresso e da imagem expositiva, fixa. Esse leitor nasceu no Renascimento e perdurou até meados do século XIX. O segundo tipo de leitor [movente] é filho da Revolução Industrial e do aparecimento dos grandes centros urbanos: o homem da multidão [...], o leitor do mundo em movimento, dinâmico, das misturas de sinais e linguagens de que as metrópoles são feitas [...]. O terceiro tipo de leitor [imersivo] é aquele que brotou nos novos espaços das redes computadorizadas de informação e comunicação (SANTAELLA, 2013a, cap. 13, p. 5).
\end{abstract}

Quase uma década mais tarde, a pesquisadora adicionou um $4^{\circ}$ tipo de leitor a este panorama: o leitor ubíquo.De acordo com Santaella (2013a, cap. 13, p. 11), "nos últimos dez anos, as transformações por que tem passado a cultura digital e a aceleração dessas transformações são de causar assombro. [...] nesse curto espaço de tempo, surgiu um quarto tipo de leitor que batizei de leitor ubíquo". SegundoSantaella $(2014$, p. 10), o leitor "é ubíquo porque está continuamente situado nas interfaces de duas presenças simultâneas, a física e a virtual [...]”. O leitor ubíquo, conectado ao Twitter enquanto pega um metrô em São Paulo, por exemplo, tem a capacidade de ocupar espaços distintos ao mesmo tempo. Enquanto ocupa o espaço físico, seu lugar de ser real e socialmente determinado (CHARAUDEAU, 2010a), ele ocupa também um espaço virtual, do ser projetado na rede (no Twitter, no Facebook, no Tumblr, no Youtube).

Em um contexto instável como esse é mais provável que a estratégia de captação fracasse em seu objetivo. A estratégia de captação (CHARAUDEAU, 2010a) pretende fazer o interlocutor entrar no universo de pensamento (o próprio ato de comunicação) e assim partilhar intencionalidade, valores e emoções do locutor. Quando a estratégia de captação não atinge este objetivo, significa que a interpretação do TU não correspondeu à intencionalidade do EU quando este enunciou seu ato de linguagem. No caso analisado, uma mensagem que pretende inspirar empatia (pelo compartilhamento do sentimento e da opinião expressos no post de Nasr), faz surgir reações de rejeição (por motivos detalhados na sequência).

Quando manifesta identificação com o discurso (o que não foi o caso), o TU abre mão tacitamente de uma prerrogativa de hostilidade ou de contestação, demonstrando frequentar o "universo de pensamento" do EU e coabitar a mesma zona de intercompreensão. Jáquando a estratégia de captação falha, o TU não se ressente em atacar o conteúdo daquele discurso, pois não deu a ele sua contrapartida de conivência. É sobre esse desencontro entre a produção e a recepção do discurso que se assenta a noção de assimetria (CHARAUDEAU, 2010a). Toda vez que um jornalista escreve algo no Twitter e não obtém a resposta esperada (ou a reação), como no caso deOctaviaNasr e de tantos outros que tiveram suas carreiras abaladas por culpa de uma breve mensagem, há um desvio, um desencontro entre a produção e a interpretação do discurso.

Como ocorre com frequência, os efeitos dessa assimetria não se limitam apenas ao contexto discursivo do ato de linguagem e podem reverberar também entre os seres determinados socialmente, o que ocorre com a transferência de efeitos do circuito interno (virtual) do ato de linguagem para o circuito externo (real), lugar dos seres sociais. $\mathrm{Na}$ comunicação ubíqua, com ritmo regido pela hipermobilidade, há uma maior propensão para essa transferência. O espaço do discurso e o espaço real nunca estiveram tão indistintos e sobrepostos; até que ponto se pode dizer que os seres sociais (circuito externo, espaço real) estão realmente fora das redes sociais (circuito interno, espaço do discurso, virtual)? O misto entre real e virtual confunde lugares e referências. De acordo com Santaella (2003, p. 128),

Os termos "realidade virtual" e "tempo real" atestam a força das novas mídias na constituição de uma cultura da simulação. As mediações se tornaram tão intensas que tudo que é mediado não pode fingir não estar afetado. A cultura é crescentemente simulacional no sentido de que a mídia sempre transforma aquilo de que ela trata, embaralhando identidades e referencialidades. 
No caso analisado, é possível observar a assimetria do ato de linguagem causada pela mistura e multiplicação de identidades e o intercâmbio de efeitos entre os espaços virtual e real. Na comunicação ubíqua, o ato de linguagem é disposto sob parâmetros diferentes. Pretendemos representá-lo conforme consta na Figura 2:

\section{Figura 2 - o ato de linguagem na hipermobilidade}

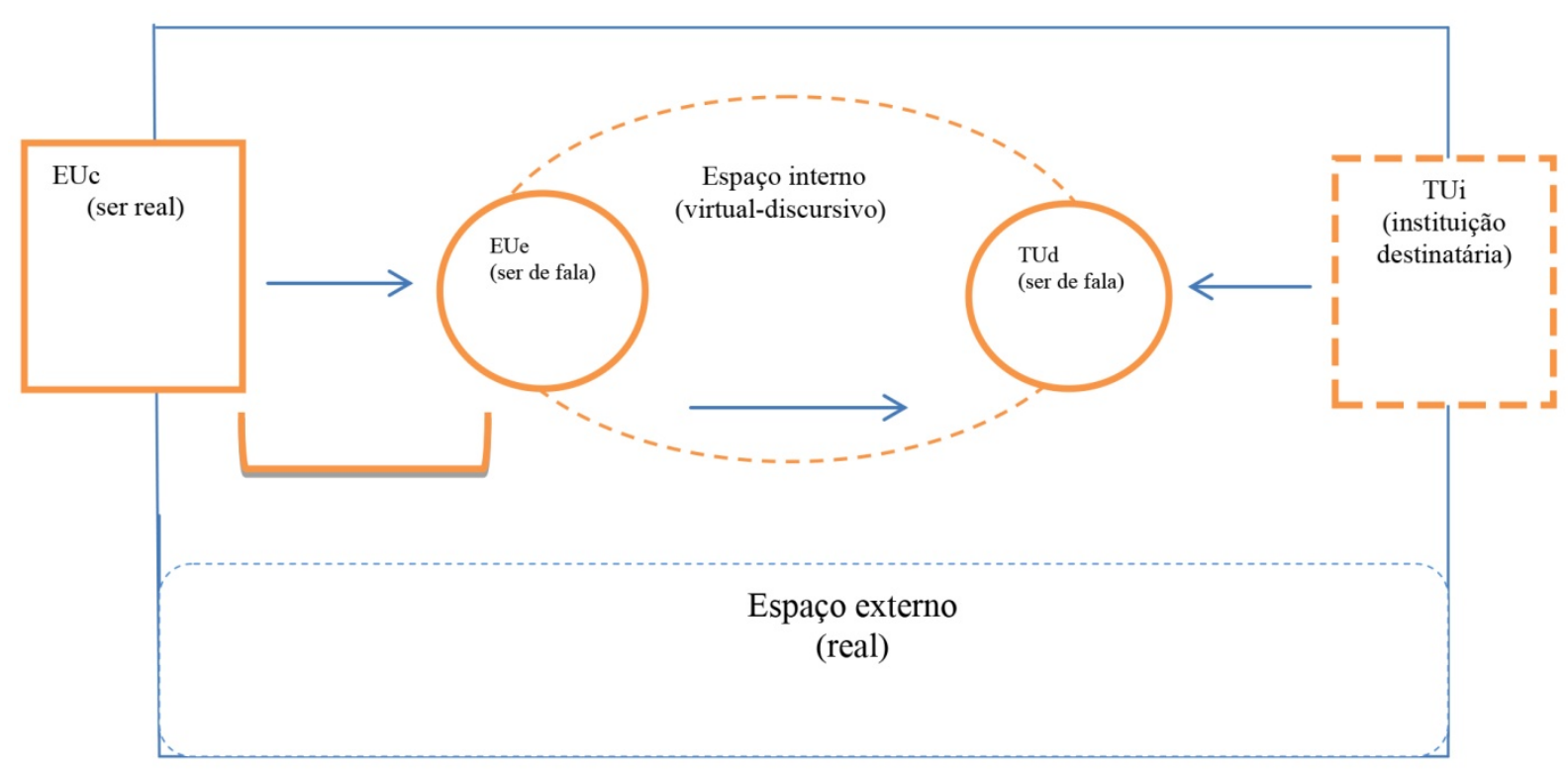

Fonte: elaborada pelo autor

Fonte: elaborada pelo autor

É importante esclarecer as representações em relação ao quadro de Charaudeau (2010a), Figura 1. O uso dos círculos no espaço interno e nos seres de fala procura representar a volatilidade das posições na hipermobilidade. A linha traçada do espaço interno e da base corresponde aos limites frágeis e muitas vezes indeterminados entre o que pertence ao real e o que pertence ao virtual. Já o traçado no TUi, instituição destinatária genérica e multifacetada composta por milhares de indivíduos distintos e sem rosto, é usado para marcar a diferença em relação à natureza do EUc, a locutora OctaviaNasr, indivíduo que, ao contrário de seu interlocutor (ou interlocutores), pode ser nomeado e está bem delimitado no espaço externo.

Como os limites que separam o espaço interno do externo, na comunicação ubíqua, são trespassáveis como uma cortina d'água, a assimetria do ato de linguagem produz mais facilmente efeitos colaterais que não atingem apenas os EUe projetados pelo locutor, mas também o ser real e determinado socialmente. O colchete horizontal representa essa ligação incontornável entre EUc e seu EUe (ser de discurso, que pode ser único ou múltiplo, como veremos). EUc projeta EUe não simplesmente em um espaço discursivo, mas em um espaço virtual-discursivo, onde EUe pode assumir diferentes faces em função da rede social usada-embora suspenso na nuvem, visto que EUeguarda uma conexão inviolável com o ser real (EUc) que representa.Como posto pela filosofia do ato responsável de Bakhtin (2012), este não-álibi no existir do sujeito, ocupante de um lugar 
único no mundo (em oposição ao leitor ubíquo e aos EUe projetados, que ocupam múltiplos lugares), impõe sobre ele a responsabilidade de responder, no espaço externo, pelo ato de linguagem disposto no espaço interno, lar dos seres de discurso.Os seres reais, habitantes do circuito externo do ato de linguagem, estão sujeitos a consequências pelo que ocorre no circuito interno do ato.

\section{Procedimentos metodológicos}

O artigo estará firmado sobre uma base teórica dividida em três princípios: [1] o ato responsável de Bakhtin (1997, 2012); [2] encenação e assimetria do ato de linguagem, de Charaudeau (2001, 2010a, 2010b) e [3] comunicação ubíqua de Santaella (2010, 2013a, 2014). Estas três bases teóricas se conectam da seguinte forma: de acordo com o quadro do ato de linguagem de Charaudeau (2010a), EUc (ser real/social) projeta EUe (ser de discurso) e TUd (ser de discurso), encenando seu ato de linguagem para TUi (ser real/social): TUi é uma instituição destinatária composta por usuários do Twitter, leitores ubíquos, (SANTAELLA, 2013a), ocupantes de dois espaços (real e virtual) ao mesmo tempo. Ainda que o ser de discurso, EUe, esteja suspenso na nuvem do hiperespaço, ele está irremediavelmente atado ao seu dúplice real (EUc), ser ocupante do espaço físico e de um lugar ímpar no mundo para quem é intransferível a responsabilidade de responder por seus atos (BAKHTIN, 2012).

1. A questão do ato responsável: Bakhtin $(1997,2012)$ defende o ato ético como a ocupação de um lugar ímpar no mundo, a partir do qual o sujeito contrai a responsabilidade de responder por seus atos ("ato responsível", como o chama Adail Sobral (2008)). De acordo com Bakhtin (2012, p. 96), não existe álibi na vida: “[...] eu também sou participante no existir de modo singular e irrepetível, e eu ocupo no existir singular um lugar único, irrepetível, insubstituível e impenetrável da parte de um outro. [...]”. O sujeito, imbuído de sua individualidade e ocupante de um lugar único no mundo, possui a responsabilidade pelo que enuncia a partir deste lugar. Enquanto ser singular, não há fuga possível às consequências do seu ato. Este inescapável preceito bakhtiniano aponta para a constituição da própria identidade do sujeito, do seu posicionamento enquanto indivíduo; um posicionamento cada vez mais difícil de apontar na comunicação ubíqua (SANTAELLA, 2013a).

2. Encenação e assimetria no ato de linguagem: Charaudeau (2001) concebe "ato de linguagem" como o combinado entre circuitos interno e externo do ato onde se estabelece o contrato de comunicação, sob o qual o sujeito desenvolve estratégias discursivas para seduzir ou persuadir seu destinatário. É sobre o desencontro entre a produção e a recepção do discurso nos circuitos interno e externo do ato que assenta a noção de assimetria (CHARAUDEAU, 2010a).

3. Assimetria do ato na comunicação ubíqua: traçar a responsabilidade pela autoria do ato de linguagem pressupõe estabelecer, a priori, o posicionamento do sujeito, o lugar (físico/histórico/cultural) a partir do qual ele enuncia. Este lugar é relativamente claro no caso de análises como a do discurso de um grande ditador do séc. XX, por exemplo. A atual "era dos fluxos", que Santaella e Lemos (2010) opõem à "era da navegação", fragmenta o sujeito, agora capaz de projetar um dúplice virtual e enunciar a partir de múltiplos espaços. Santaella (2014, p. 10) chama este fenômeno de "hipermobilidade, ou seja, a mobilidade física fundida à mobilidade da informação nas redes".

Compõe o corpus do artigo umtweet da jornalista libanesa e analista política para assuntos do Oriente Médio OctaviaNasr. Convém destacar que o fato de o corpus ser composto por um único tweet depõe em favor dessa fatalidade relacionada ao poder de influência (e potencial para devastação) que a rede Twitter possui, ainda que a ferramenta, 
para gerar um fato extremamente influente e de grandes consequências, esteja contida em 140 caracteres ou menos ${ }^{60}$. Do mesmo modo, ressaltamos que a análise aqui descrita não se propõe uma análise geral que se ocupa do funcionamento de toda e qualquer comunicação realizada no Twitter, mas uma análise específica, que investiga a força e a influência que um único tweet pode exercer.

\section{Assimetria, ato ético e ubiquidade: um tweet sob análise}

Não há como ignorar as altas tensõessociopolíticas envolvendo os Estados Unidos e os países do Oriente Médio antes de darmos atenção especificamente à demissão de OctaviaNasr, que, embora tenha tido uma causa majoritariamente linguística, está ligada, sobretudo, à "guerra contra o terrorismo" (em nome do foco, definições de perspectiva acerca do uso da palavra "terrorismo" podem ficar para um artigo futuro) promovida pelo governo norte-americano pós-11/09.

OctaviaNasr é uma jornalista nascida no Líbano,país marcado por conflitos históricos tanto internamente quanto com seus vizinhos do Oriente Médio, ocupado por um povo fraturado por milhares de anos de guerras e divergências religiosas. O Hezbollah ("partido de Deus", em árabe), uma organização paramilitar xiita criada em 1982, é resultado de um desses conflitos mais recentes: a Guerra Civil do Líbano. O Hezbollah, embora reconhecido como um grupo de atuação política e de resistência legítimo por grande parte das nações árabes, é considerado uma organização terrorista por muitos países do Ocidente, entre eles os Estados Unidos. Mohamed Hussein Fadlalah, aiatolá xiita e guia espiritual do grupo desde o início do movimento, era, assim como o Hezbollah, considerado terrorista pelo governo norteamericano. Dentro dessa conjuntura, uma jornalista de uma empresa norte-americana que lamenta publicamente a morte de um homem considerado terrorista por este país se torna, imediatamente, má representante da imagem desta empresa e vulnerável a consequências.

A transcrição exata do tweet que causou a demissão de OctaviaNasr, seguido da hashtag "\#Líbano", é a seguinte: "Triste ao saber da morte de Sayyed Mohammad Hussein Fadlallah. Um dos gigantes do Hezbollah a quem respeito muito... \#Líbano" (tradução nossa) ${ }^{61}$.

A mensagem de Nasr é um ato de linguagem proposto pela locutora a um destinatário ideal e para o qual ela aguarda uma contrapartida de conivência. OctaviaNasr (EUc) escreve projetando um ser de discurso (EUe) idealizado para transmitir empatia e respeito pela morte de um grande líder político e religioso (Fadlallah). Ao projetar EUe, ente discursivo, a locutora projeta também um destinatário idealizado (TUd), uma instituição destinatária composta por libaneses (intenção expressa no uso da hashtag "Líbano") e por leitores de outras nacionalidades, incluindo norte-americana. Esse sujeitoTUd, também projetado, cuja existência resume-se ao desempenho do ato, corresponde às expectativas linguageiras que o EUc alimenta para o ato de comunicação. "O EUc é o iniciador-responsável pelo ato de produção e é a relação EUc-EUe que produz um certo efeito pragmático sobre o Interpretante" (CHARAUDEAU, 2010a, p. 52).

Otweet de OctaviaNasrfoilido com tal relevância por TUi não em funçãode suas preferências pessoais ou visão de mundo, mas por sua posição enquanto analista política e formadora de opinião em uma grande empresa de comunicação norte-americana. O nome usado pela jornalista no Twitter não é simplesmente "octavianasr", mas "octavianasrCNN": o empregador como sobrenome.Esse detalhe traz consequências: não é apenas um único EUe,

\footnotetext{
${ }^{60}$ Isso antes da atualização de 2017 que ampliou o limite para 280 caracteres.

${ }^{61}$ Sad to hear of the passing of Sayyed Mohammad Hussein Fadlallah. One of Hezbollah's giants I respect a lot. \#Lebanon.
} 
sujeito de discurso, que precisa ser considerado no ato de linguagem executado de fato e percebido pelo TUi, mas dois: o EUe projetado de acordo com a estratégia discursiva de Nasr(que chamaremos de "EUe-pessoal") e um EUe projetado involuntariamente e percebido por TUi como fonte real da mensagem (que chamaremos de "EUe-profissional").

O EUe-pessoal, previsto no projeto de fala de Nasr, representa a OctaviaNasr libanesa, com opinião (expressa na palavra "respect/respeito") e sentimento ("sad/triste") próprios, características de ordem pessoal. Como objetos da ordem pessoal do sujeito, opinião e sentimento podem ser admitidos.OEUe-profissional, projetado involuntariamente, representa OctaviaNasrenquanto profissional e porta-voz da norte-americana CNN (como explícito nas cores vermelha e branca, na foto que ilustra sua página, vestindo um terno da emissora, e em seu nome na rede social). Sentimento e opinião são duas características não admitidas normalmente tanto para conglomerados de comunicação quanto para jornalistas, profissão sobre a qual pesa o mito da frieza e imparcialidade. TUi, instituição destinatária, percebe o tweet de Nasr como proveniente de EUe-profissional, jornalista da CNN. O ato de linguagem como ocorrido efetivamente, com esta projeção dupla de sujeitos de discurso pelo EUc, pode ser representado conforme Figura 3:

\section{Figura 3 - o ato de linguagem no caso OctaviaNasr}

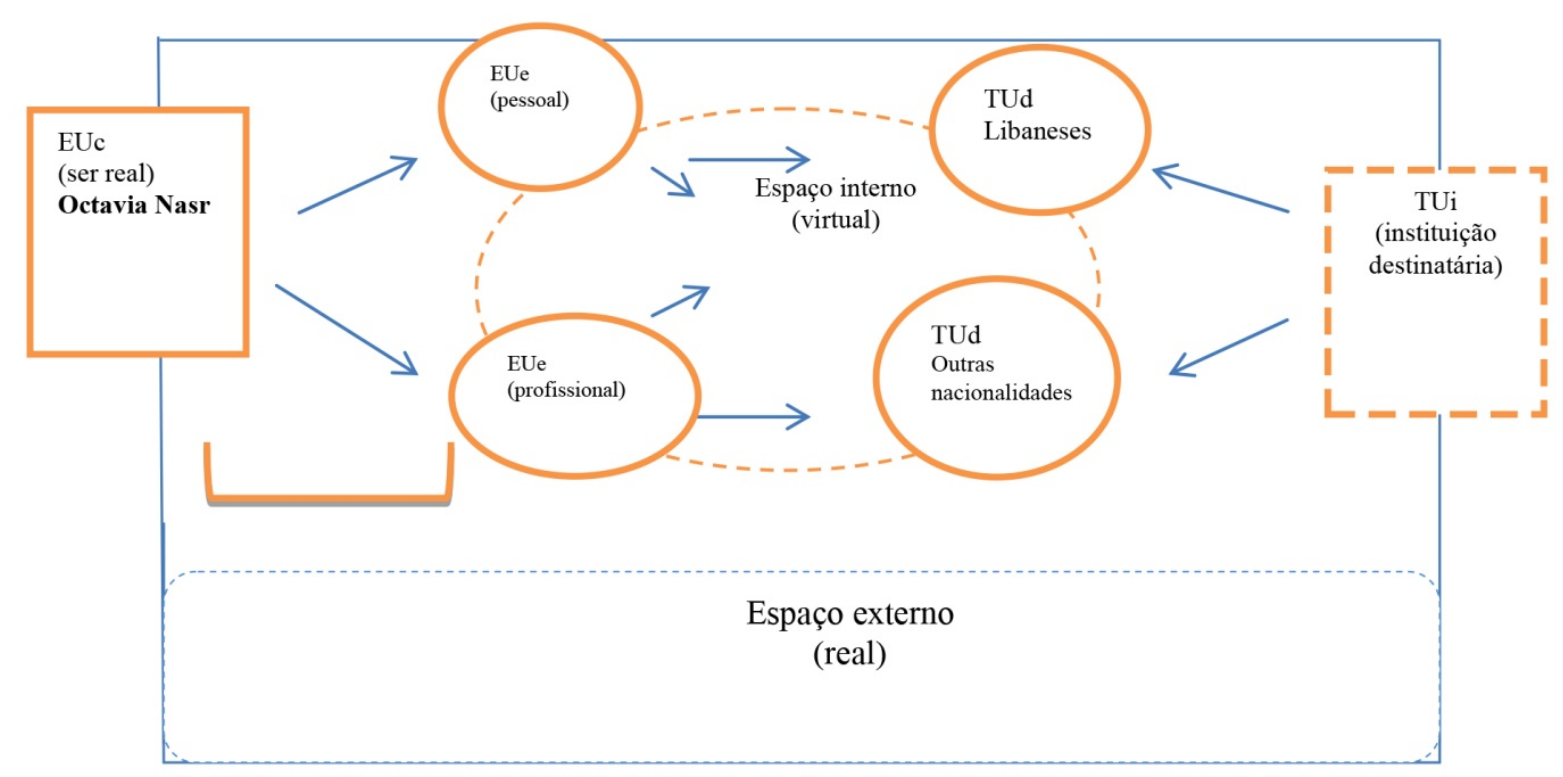

Fonte: elaborada pelo autor

O primeiro EUe projetado pela locutora é o EUe do usuário comum (EUe-pessoal), que escreve um comentário pessoal em sua conta no Twitter, aquele usuário desvinculado de entidades mais ou menos abstratas como "jornalista", das quais o leitor pode esperar que guarde ou mesmo "honre" determinadas características (como imparcialidade, por exemplo). Trata-se de um EUeproposto de acordo com as estratégias discursivas da locutora. O EUepessoal possui legitimidade ao emitir opinião e sentimento acerca de um tema sobre o qual, para o EUe-profissional (projetado involuntariamente), esses elementos são vetados pelo interpretante. Sendo esse o quadro da situação de comunicação, a estratégia de captação não atinge sua finalidade precisamente por captar o interlocutor a partir do EUeindevido, ou seja, o EUe-profissional sem legitimidade para contemplar o assunto sob a perspectiva subjetiva e emocional(que pertence ao EUe-pessoal) e que não fazia parte do projeto de fala do locutor, 
mas que foi projetado à revelia das suas estratégias de discurso e percebido por TUi como o legítimo representante de EUc (sujeito social/real).

EUe-pessoal é direcionado a dois diferentes TUd projetados (o que é representado no esquema pelos dois vetores paralelos um ao outro): o primeiro representa um conjunto de leitores libaneses (incitados diretamente à leitura do tweet pela hashtag "\#Líbano"), de que Nasr esperava algum vínculo de empatia com a mensagem, leitores que compartilhariam ou ambos ou pelo menos um dos elementos de ordem pessoal explícitos na mensagem (tristeza e respeito); e o segundo de leitores de outras nacionalidades, não necessariamente dispostosao mesmo vínculo de empatia, mas de algum modo tolerantes em relação ao seu teor por perceber que ali estava OctaviaNasr pessoa, conforme seu EUe-pessoal projetado voluntariamente (em oposição ao EUe-profissional, projetado involuntariamente), dentro de seu projeto de fala e estratégia discursiva, e não a jornalista e analista política da $\mathrm{CNN}$, da qual tal mensagem não seria admitida.

Como Charaudeau (2010a, p. 45) destaca, o ato de linguagem é um ato interenunciativo entre quatro sujeitos, "lugar de encontro imaginário de dois universos de discurso que não são idênticos", o universo de produção que parte do EU e o universo de interpretação dirigido pelo TU. Quando o universo do TU revela uma interpretação incompatível com a postulada no universo de produção do EU, a estratégia de captação não produzirá o resultado esperado, e EU não conseguirá com que TU partilhe de sua intencionalidade, valores e emoções. TUi, ser social, instituição destinatária composta pela massa heterogênea de leitores/usuários do Twitter, recebe a mensagem de Nasr de forma negativa em razão da projeção, inadvertidamente, do segundo EUe: o EUe-profissional, residual, inapartável do EUe que o locutor projeta todos os dias como parte de sua atividade profissional (como parte de EUc). Para o TUi, a mensagem é percebida não como que emitida pelo primeiro EUe, pessoal, mas pelo segundo, jornalista, o que transforma o teor dessa mensagem em algo incompatível com o que TUi espera de EUc, gerando assimetria entre produção e interpretação do discurso.

Convém analisar a composição desseTUi do ponto de vista da comunicação ubíqua de Santaella (2013a). Como transita a mensagem a partir de EUc, ser real, ocupante de um espaço físico, passando pelo universo virtual e chegando até os milhares de usuários que formam a instituição destinatária? Em suma, como transita essa mensagem na era da hipermobilidade? Como define Santaella (2013a, p. 5), "ahipermobilidade cria espaços fluidos, múltiplos não apenas no interior das redes, como também nos deslocamentos espaçotemporais efetuados pelos indivíduos". Os leitores do Twitter não são somente contemplativos, moventes ou imersivos - eles são ubíquos. O TUi da hipermobilidade é ubíquo, ocupante de múltiplos espaços ao mesmo tempo, ao passo que prever sua posição e projetar o TUd(ser de discurso) que corresponda mais proximamente ao TUi(ser social) é o grande desafio da encenação do ato de linguagem na comunicação ubíqua. Como dispõe Santaella (2013a, p. 21), esse leitor ubíquo pode, com um toque no celular, "penetrar no ciberespaço informacional, assim como pode conversar silenciosamente com alguém ou com um grupo de pessoas a vinte centímetros ou a continentes de distância". O que o caracteriza, Santaella (2013a, p. 21) acrescenta, é ser capaz de "orientar-se entre nós e nexos multimídia sem perder o controle da sua presença e do seu entorno no espaço físico em que está situado".

Isso significa ser necessário que o locutor, além de desconhecer os rostos e o gestual de seus destinatários, tampouco seus dados pré-discursivos, assuma também a probabilidade de não dispor de toda a sua atenção no momento em que ele lê sua mensagem. Como um leitor ubíquo, há múltiplos espaços - além do espaço discursivo onde transcorre o ato de linguagem- que demandam sua vigília. E além de múltiplos espaços, há múltiplos leitores compondo este TUi endereçado pela locutora. Ao contrário de um ato de linguagem proposto em um simples diálogo, por exemplo, o tweet de Nasr fora escrito para usuários em geral, não 
para um indivíduo, e esses usuários formam uma instituição destinatária não apenas densamente heterogênea e composta por pessoas de nacionalidades diferentes e em diversas partes do mundo - um TUd fragmentado e multifacetado em sua essência-, mas também um TUd composto por pessoas de visões opostas em relação ao tema do tweet- por um lado, pessoas de um país onde o Hezbollah é um partido oficial no Governo, e, por outro, pessoas de países que tratam esse partido como uma organização terrorista.

$\mathrm{Se} \mathrm{o}$ ato de linguagem se portava sobre plataformas sólidas, na hipermobilidadea analogia cabível é exatamente oposta.O locutor precisa antecipar que lida com umTUi ubíquo, ao mesmo tempo exposto mas anônimo, presente na tela mas que desaparece assim que se procura identificá-lo e compreendê-lo.Estilhaçado em diversos espaços simultâneos, o leitor ubíquo tem quebrada também sua atenção e seu tempo hábil para lidar com cada espaço que umduplo seu ocupa em um mesmo intervalo de tempo. Conforme Charaudeau (2010a, p. 52), "o ato de linguagem não pode ser considerado somente como um ato de comunicação: tal ato não é apenas o resultado de uma única intenção do emissor e não é o resultado de um duplo processo simétrico entre Emissor e Receptor”. Em uma conjuntura de comunicação ubíqua, pelos motivos já comentados, o ato de linguagem é muito mais suscetível a sofrer com certa assimetria, o que emprega mais força às palavras de Charaudeau (2010a,p. 57) quando o linguista nos diz que o ato de linguagem é "não apenas uma expedição, mas também uma aventura".

Podemos verificar que o leitores perceberam apenas o EUe-profissional projetado involuntariamente por OctaviaNasr, não o EUe-pessoal. O EUe-profissional é o mais próximo doEUc(sujeito real) de Nasr, pois aponta para sua posição no mundo social, posição a partir da qual Nasr se projeta para o mundo diariamente em função de sua profissão e de sua posição na CNN. Para o público que a acompanha no Twitter, seja libanês, norte-americano ou de qualquer nacionalidade, a identidade de Nasr é definida pela sua posição na cadeia de notícias CNN. Esta é sua posição no mundo real, o espaço ocupado enquanto ser social pela jornalista, de modo que ela não pode fugir à posição que a define para o mundo. Como afirma Bakhtin (2012), a singularidade do existir é irrevogavelmente obrigatória. Sobral (2008), em sua pesquisa sobre a filosofia do ato responsável bakhtiniana, reafirma que, para Bakhtin, "não há álibi na existência", e os atos do sujeito, sejam ou não voluntários, são responsabilidade sua, ou melhor, "responsibilidade" sua, isto é, responsabilidade pelo ato e responsividade aos outros sujeitos no âmbito das práticas em que são praticados os atos". (SOBRAL, 2008, p. 228, grifo nosso).

Este preceito bakhtiniano torna ilegítima qualquer tentativa do sujeito de se isentar e fugir à responsabilidade pelo seu ato de linguagem. Ainda que esteja suspenso no plano virtual, no espaço interno do ato de linguagem (contexto de comunicação, espaço discursivo), qualquer EUe projetado, encobrindo total ou parcialmente EUc, estará irreversivelmente ligado a ele no espaço externo do ato de linguagem (situação de comunicação, espaço dos seres sociais). EUc, diferentemente de EUe, não é inapreensível como uma lâmina de vapor, desaparecendo assim que se procura confiná-lo no espaço virtual - EUc é real, está amarrado a quaisquer EUe que projetar do espaço físico que ocupa, e sofrerá consequências impostas por outros seres sociais que compõem a instituição destinatária TUie que não engajarem em seu projeto de fala, não concedendo também sua contrapartida de conivência, levando à assimetria do ato.

Comunicar, comentaCharaudeau (2010a, p. 68, grifo do autor), “é proceder a uma encenação [...] para produzir efeitos de sentido visando um público imaginado [...]". Conforme Freitas (2011, p. 120), "todo ato de linguagem [...] é, afinal de contas, uma representação comandada por sujeitos externos [...]. Todos nossos atos de linguagem têm um lado "teatral' [...]", a partir do qual representamos ou nos colocamos "em cena" (na cena de comunicação, discursiva) de uma determinada maneira, buscando infligir efeitos específicos 
(efeitos de discurso).OTUiubíquo, densamente estratificado, recebeu a mensagem de múltiplas posições e múltiplas perspectivas, em sua maioria rejeitando os elementos de ordem pessoal (opinião e sentimento) por perceberem apenas o EUe projetado inadvertidamente(EUe-profissional) e cuja posição, como já vimos, não admite tais aspectos valorativos. Para esse público, aquela não era OctaviaNasr, mas, por assim dizer, "octavianasrCNN", de modo que não haveria como obter contrapartida de conivência de um público ao expressar empatia por uma figura que o governo federal deste mesmo público considera um líder terrorista.

Nasr propôs um ato de linguagemem uma plataforma de comunicação ubíqua (em que os atores do discurso são ocupantes de múltiplos espaços simultaneamente). Suas estratégias discursivas de legitimidade e de captação não atingiram sua finalidade em função da percepção de TUi do EUe-profissional (projetado involuntariamente), mais transparente e revelador de EUc que o EUe-pessoal (projetado voluntariamente), o que levou a uma assimetria do ato de linguagem: o interpretante considerou que a locutora não tinha legitimidade e não estava em uma posição adequada para emitir a mensagem em questão e, portanto, não compartilhou de sua intencionalidade, valores e emoções (CHARAUDEAU, 2010a).Consequentemente, por EUe (ainda que duplo, múltiplo) estar ligado a EUc, e este ocupar um lugar único no mundo, a locutora viu-se sob a responsabilidade de responder por este ato (responsibilidade). Por esta razão, sua demissão da CNN.

\section{Considerações finais}

Seria este tempo de redes sociais recente demais, portador de revoluções velozes demais para adaptação dos usuários, mesmo os profissionais de comunicação? Ou seria o caso de as redes exporem como nunca antes a intimidade da construção do pensamento, da opinião e, portanto, das convicções e (quando for o caso) preconceitos antes ocultos sob uma noite de sono, sob uma revisão editorial criteriosa? As redes sociais, em especial o Twitter, podem revelar quase que em tempo real a reação e o processo de raciocínio de um usuário ou de uma massa de usuários (através do acompanhamento dos trendingtopics). $\mathrm{O}$ número de casos de demissão e outros reveses ocorridos por uma mensagem postada em uma rede social pode ser explicado por essas questões, o que não significa que prescindimos de uma avaliação mais criteriosa a respeito dos mecanismos que levam à assimetria desses atos de linguagem, sobretudo pela plataforma em que são encenados e pelo tipo de destinatário ao qual são direcionados.

Neste artigo procuramos investigar a assimetria entre os processos de produção e de interpretação do discurso encenado no Twitter, em um contexto de comunicação ubíqua e cujas consequências encontram o ser real em função deste ato de linguagem se tratar de um ato ético - projetado através de múltiplos seres de discurso e para destinatários ocupantes de múltiplos espaços, mas enunciado a partir de uma posição única no mundo social. Compõe o corpus do artigo o tweet da jornalista libanesa e analista política para assuntos do Oriente MédioOctaviaNasr, até então profissional da CNN, a respeito da morte do aiatolá xiita Sayyed Mohammad Hussein Fadlallah em julho de 2010.

Averiguamos que as estratégias discursivas de legitimidade e de captação não atingem seus objetivos e há assimetria no ato de linguagem.Nasr projeta um EUe-pessoal de acordo com suas estratégias de discurso, legitimado para fazer comentários carregados de opinião (expressa na palavra "respeito") e sentimento (expressa na palavra "triste"). Contudo, Nasr projeta também um EUe-profissional, que não acoberta EUc da mesma forma que o EUepessoal. Primeiramente, a estratégia de legitimidade falha por TUi perceber apenas EUeprofissional e ficar mais próximo da posição de Nasr no mundo real enquanto jornalista da CNN. Para TUi, instituição destinatária composta por leitores ubíquos, EUe-profissional não 
tem legitimidade para comentar a morte do aiatolá xiita com elementos como opinião e sentimento. Em segundo lugar, falha a estratégia de captação por não conseguir fazer o destinatário habitar o mesmo universo de pensamento do locutor e partilhar de seus valores e emoções (CHARAUDEAU, 2010a).

A comunicação ubíqua (SANTAELLA, 2013a) torna áspera a tarefa de elaborar estratégias discursivas para destinatários que ocupam múltiplos espaços simultâneos e estão ocultos por trás de suas contas nas redes sociais. Não seria possível, não importa a estratégia de discurso usada para transmitir sentimento ("triste") e opinião ("respeito"), obter uma simetria do ato de linguagem de modo geral. A única forma para que a mensagem não fosse rejeitada seria a retirada, como proposto pela própria jornalista em entrevista posterior ${ }^{62}$, das palavras que expressavam esses aspectos valorativos. Por fim, apesar de suspender na nuvem múltiplos EUe, o ser real EUc está ligado a cada um deles a partir de sua posição no mundo real - no caso analisado, a posição de Nasr é composta por fatores como origem e nacionalidade, profissão (valores ligados a essa profissão) e ligação de trabalho com uma empresa de comunicação norte-americana. Por ocupar um lugar único e irrepetível no mundo (BAKHTIN, 2012), Nasr tem a responsabilidade de responder por seu ato - neste caso, sua demissão da CNN.

O impulso para externar todo e qualquer pensamento, tornado prático pelo acesso imediato à tribuna digital (o slogan original do Twitter, logo quando lançado, era uma pergunta provocante: “o que você está pensando?”), é capaz de explicar apenas uma parte da questão. É comum vermos pessoas públicas não profissionalmente ligadas ao jornalismo, como atores, modelos e atletas, recebendo pesadas críticas e até mesmo perdendo contratos e patrocínios por algo dito em uma rede social - mas por que o mal do post desastrado recai com tanta frequência (e impacto) exatamente sobre quem trabalha com comunicação é o aspecto para o qual pretendemos oferecer respostas com este artigo. Procuramos entender o fenômeno, avaliar quais as estratégias discursivas, por que elas não têm o efeito desejado e por que as consequências do que é dito no universo virtual do discurso provoca devastação no universo real, dos seres socialmente determinados.

\section{REFERÊNCIAS}

BAKHTIN, Mikhail. Estética da criação verbal. 2.ed. São Paulo, SP: Martins Fontes, 1997. . Para uma filosofia do ato responsável. São Paulo: Pedro \& João Editores, 2012.

CHARAUDEAU, Patrick.Uma teoria dos sujeitos da linguagem. In: MARI, Hugo; MACHADO, Ida Lúcia; MELLO, Renato. (Orgs.). Análise do discurso: fundamentos e práticas. Belo Horizonte: NAD/FALE/UFMG, 2001.p. 23-37.

; MAINGUENEAU, Dominique. Dicionário de análise do discurso. São Paulo: Editora Contexto, 2008.

Linguagem e discurso: modos de organização. São Paulo, SP. 2010a.

Discurso das Mídias. São Paulo, SP. 2010b.

FREITAS, Ernani Cesar de. Cultura, linguagem e trabalho: comunicação e discurso nas organizações. Desenredo, Passo Fundo: Ed. da Universidade de Passo Fundo, v. 7, n. 1, p. 104-126, jan./jun. 2011.

NASR, Octavia. Fired over a tweet, Octavia Nasr says journalists need protection from social media flame wars. In.:Ijnet, 2012. Disponível em: $<$ http://ijnet.org/blog/fired-over-tweetoctavia-nasr-says-journalists-need-protection-social-media-flame-wars $>$. Acesso em: 13 abr. 2016.

SANTAELLA, Lucia. Matrizes da linguagem e pensamento. São Paulo: Iluminuras, 2001.

62 "If I must tweet, I would've tweeted that he passed away without any extra information". 
. Culturas e artes do pós-humano: da cultura das mídias à cibercultura. São Paulo: Paulus, 2003.

Navegar no Ciberespaço - O perfil cognitivo do leitor imersivo. São Paulo: Paulus, 2004.

; LEMOS, Renata. Redes sociais digitais: a cognição conectiva do Twitter. São Paulo: Paulus, 2010.

Comunicação ubíqua: repercussões na cultura e na educação. [E-BOOK]. 1a.ed. São Paulo: Paulus, 2013a.

Desafios da ubiquidade para a educação. In.:Ensino Superior UNICAMP, 2013b.

Disponível em: $<$ https://www.revistaensinosuperior.gr.unicamp.br/artigos/desafios-daubiquidade-para-a-educacao $>$. Acesso em: 16 jun. 2016.

. Sociotramas: estudos multitemáticos sobre redes digitais. 1. ed. São Paulo: Estação das Letras e Cores, 2014.

SOBRAL, Adail. O ato "responsível" ou ato ético, em Bakhtin, e a centralidade do agente. RevistaSignum. Estudos de Linguagem, Londrina, PR, v.11, 2008, p. 219 - 235.

Recebido em 02/08/2017

Aceito em 28/11/2017 